\title{
Transmisión y apropiación de la historia de prisión política: transgeneracionalidad del trauma psicosocial en nietos de ex presos políticos de la dictadura militar chilena
}

\section{Transmission and appropriation of political imprisonment stories: The transgenerational nature of psychosocial trauma in grandchildren of former political prisoners of the chilean military dictatorship}

\author{
Ximena Faúndez \\ Universidad de Valparaíso, Chile \\ Marcela Cornejo \\ Pontificia Universidad Católica de Chile, Chile \\ Jean-Luc Brackelaire \\ Université Catholique de Louvain, Bélgica
}

(Rec: 07 agosto 2013 / Acept: 27 noviembre 2014)

\begin{abstract}
Resumen
Se presentan resultados de un estudio que abordó la transmisión transgeneracional del trauma psicosocial en la tercera generación de víctimas de la dictadura militar chilena. Participaron 14 jóvenes, nietos de ex presos políticos, de 21.4 años de edad en promedio, provenientes de las regiones Metropolitana y de La Araucanía. Mediante el uso de relatos de vida, se les solicitó contar su historia como nieto de una persona víctima de prisión política. Los resultados permiten distinguir un proceso narrativo que, desde ciertas etapas, va articulando la historia de vida de los nietos, inscribiéndola en una lógica de transmisión y apropiación transgeneracional del trauma psicosocial asociada a la historia y memoria familiar respecto a la experiencia traumática, persistiendo en sus familias una dinámica de evitación y de silencio en torno a la experiencia de tortura, la que determina las particularidades de la relación de los nietos con esta experiencia traumática. Palabras clave: transmisión transgeneracional, trauma psicosocial, narración, elaboración y tercera generación.
\end{abstract}

\begin{abstract}
The article presents the results of a study on the transgenerational transmission of psychosocial trauma in the third generation of victims of the Chilean military dictatorship. The participants were 14 young people, grandchildren of former political prisoners, aged 21.4 on average, living in the Metropolitan and Araucanía regions. They were asked to use life stories to share their experiences as grandchildren of victims of political imprisonment.

The results reveal a narrative process, which, beginning at certain stages, articulates the life stories of grandchildren framing it in a logic of transmission and transgenerational appropriation of the psychosocial trauma associated with the family's history and memory about the traumatic experience. Families remain engaged in a dynamic of avoidance and silence regarding the experience of torture, which determines the characteristics of the relationship of grandchildren with this traumatic experience.

Keywords: transgenerational transmission, psychosocial trauma, narration, psychological processing, third generation.
\end{abstract}

Correspondencia:

Nota de Autor: Los resultados presentados corresponden a la Tesis para optar al grado de Doctor en Psicología de la Pontificia Universidad Católica de Chile, desarrollada por Ximena Faúndez Abarca. La investigación contó con financiamiento de la Comisión Nacional de Investigación Científica y Tecnológica de Chile (CONICYT) y del Museo de la Memoria y los Derechos Humanos de Chile.

La correspondencia relativa a este artículo debe ser dirigida a Ximena Faúndez, Escuela de Psicología, adscrita al Convenio de Desempeño para las Humanidades, Artes y Ciencias Sociales de la Universidad de Valparaíso. Blanco 1215, Of. 101, Valparaíso, Chile. E-mail: ximena.faundez@uv.cl

Marcela Cornejo, Escuela de Psicología, Pontificia Universidad Católica de Chile, Vicuña Mackenna 4860, Macul, Santiago, Chile. E-mail: marcela@uc.cl Jean-Luc Brackelaire,Institut d'Analyse du Changement Dans l'Histoire et les Sociétés Contemporaines, Université Catholique de Louvain et Université de Namur, Bélgica. E-mail: jean-luc.brackelaire@uclouvain.be 


\section{Introducción}

Un total de 38.254 personas han sido reconocidas por el Estado chileno como víctimas de privación de libertad por razones políticas durante la dictadura militar, entre septiembre de 1973 y marzo de 1990. Este número solo representa los casos de quienes voluntariamente declararon ante las comisiones de prisión política y tortura y cuyas declaraciones fueron posteriormente calificadas, lo que permite pensar-de acuerdo a estimaciones de organizaciones de derechos humanos- que las víctimas son aún más. La primera de estas instancias fue la Comisión Nacional sobre Prisión Política y Tortura (en adelante CNPPT), la cual calificó un total de 28.459 casos de los 35.868 que declararon (CNPPT, 2004). La segunda es la Comisión Presidencial Asesora para la Calificación de Detenidos Desaparecidos, Ejecutados Políticos y Víctimas de Prisión Política y Tortura (en adelante CPACDD), la cual calificó 9.795 casos de los 31.841 que declararon (CPACDD, 2011). La importancia fundamental del trabajo de estas comisiones es que después de más de 30 años del golpe militar del 11 de septiembre de 1973, el Estado chileno otorgó un reconocimiento oficial a la aplicación masiva y sistemática de la tortura por agentes del Estado o personas a su servicio (Cornejo, Rojas, Buzonni, Mendoza, Concha y Cabach, 2007; Lira, 2011).

La tortura es una forma extrema de exposición a la violencia, irreductible al repertorio de agresiones físicas y psicológicas que la componen. Se trata de actos premeditados y planificados, cuyo objetivo es destruir las creencias y convicciones de la víctima, despojándola de los elementos que constituyen su identidad (Améry, 1966/2010; Viñar, 2006). El carácter traumático de la tortura está dado por el impacto sorpresivo e inesperado de las múltiples amenazas vitales, y por la consecuente desorganización experimentada por los sujetos, familias y grupos sociales (Deutsch, 2007; Lira 1990; Lira y Castillo, 1991).

Durante la dictadura militar chilena, los sobrevivientes de la tortura debieron reintegrarse a la vida familiar y social, en un entorno afectado por el silencio y la negación de las acciones de violencia política (Lira y Castillo, 1991; Lira, Becker y Castillo, 1989), así como por la impunidad de quienes cometieron estos hechos. Esto generó, tanto en las víctimas directas como en su medio familiar y social más amplio, consecuencias que permanecen a través del tiempo, marcando las relaciones que establecen.

La tortura, dado su carácter traumático, adquiere particular relevancia y significado en la historia de las víctimas y sus familias. Según el informe de la CNPPT, "casi todos consideraban que la prisión y la tortura habían tenido efectos devastadores en sus vidas. A los trastornos de su salud física y mental se sumaba la perturbación de sus relaciones sociales, afectivas y sexuales, que llegó a deteriorar, a menudo, los vínculos con sus familiares y sus parejas, lo que causó, en muchos casos, rupturas insalvables" (Informe CNPPT, 2004, p. 495). Frente a la complejidad de las consecuencias de esta experiencia se hace evidente la insuficiencia de las categorías diagnósticas de los síndromes psiquiátricos para dar cuenta de la problemática de las víctimas de violencia política. Esto llevó a diversos autores a reemplazar estas categorías clínicas por el concepto de trauma psicosocial propuesto por Martín-Baró (1989), el cual señala que tanto el origen como las consecuencias del trauma se encuentran en las relaciones sociales. Esta conceptualización permite la comprensión etiológica y el abordaje de los síntomas, reconociendo la dimensión sociopolítica de la violencia y al individuo en su dimensión social.

Estudios realizados en diversas partes del mundo dan cuenta que los traumas psicosociales no solo afectan a las víctimas directas, sino que tienen consecuencias sobre varias generaciones de descendientes, fenómeno que ha sido llamado transmisión transgeneracional del trauma (Volkan, 1996). Entre los autores de estos estudios no existe acuerdo en calificar a los hijos de las víctimas directas, como segunda generación. Para algunos (Minoletti, 2002), los hijos nacidos antes o durante la ocurrencia de los hechos de violencia pertenecen a la primera y no a la segunda generación de víctimas, ya que los hijos sufrieron las experiencias de amedrentamiento, allanamiento, detención y/o desaparición de los padres. Para otros autores (Bekerman, Soutric, Pezet, Mazur, Oberti y Lagos, 2009; Brinkmann, Guzmán, Madariaga y Sandoval, 2009), los hijos de víctimas directas nacidos en democracia pertenecerían no a la segunda sino a la tercera generación, ya que no habían nacido cuando ocurrieron los hechos de violencia política. Sin embargo, para efectos de una mayor comprensión de este escrito, utilizaremos en adelante el concepto de primera generación para referirnos a las víctimas directas de la prisión política y la tortura, el concepto segunda generación para referirnos a sus hijos y el de tercera generación para referirnos a sus nietos.

La mayor parte de las investigaciones se han centrado en la transmisión entre la primera y segunda generación de víctimas del Holocausto (Barocas y Barocas, 1973; Lev-Wiesel, 2007; Rowland-Klein, 2004), existiendo en la actualidad estudios con terceras generaciones (Bender, 2004; Rosenthal, 1998). En un principio, la investigación se centró en los aspectos psicopatológicos de la población y posteriormente en las relaciones familiares, estudiándose 
por ejemplo, patrones de comunicación y el sobre involucramiento de los padres en la vida de sus hijos.

En relación a las dictaduras militares latinoamericanas de los años 70, Becker y Díaz (1998), Biedermann (1991), Brinkmann et al. (2009), Faúndez, Estrada, Balogi y Hering (1991) y Díaz (1995) en Chile; Edelman, Kordon y Lagos (1998) en Argentina; Cardoso, Calhau, Knijnik, Kolker y Vital (2009) en Brasil, y Scapusio, Pache, Ortiz y Ruiz (2009) en Uruguay, han desarrollado investigaciones en torno a los efectos de la violencia política en la segunda generación. Sin embargo, no existen estudios que aborden el fenómeno de la transmisión del trauma a la tercera generación, es decir a los nietos de las víctimas directas.

El presente artículo se basa en un estudio realizado en Chile cuyo objetivo fue comprender la forma en que el trauma psicosocial se transmite e integra en las trayectorias vitales de la tercera generación de víctimas de prisión política y tortura (en adelante PPT) de la dictadura militar chilena. En este se expondrán y discutirán específicamente los resultados relativos a la forma que tomó la narración de las historias de los nietos en torno a la experiencia de PPT de sus abuelos, analizando cómo esta historia se ha ido transmitiendo, apropiando y asumiendo significados en sus propias historias de vida, a través de la manera que tuvieron de contarla.

\section{Trauma psicosocial y transmisión transgeneracional}

En Latinoamérica, Ignacio Martín-Baró (1989), tras analizar las consecuencias del conflicto armado de El Salvador en los años 80, propone el concepto de trauma psicosocial para referirse a los problemas ligados a dicho proceso histórico, definiéndolo como "la herida provocada por la vivencia prolongada de una guerra. La herida o afectación dependerá de la peculiar vivencia de cada individuo, vivencia condicionada por su extracción social, por su grado de participación en el conflicto, así como por características de su personalidad y experiencia" (Martín-Baró, 1990, p. 4).

Como plantea Martín-Baró (1989), la institucionalización de la violencia como medio de dominación da paso a un trauma psicosocial, en el que diversos ámbitos propios de lo humano se ven trastocados, como la posibilidad de establecer comunicaciones sinceras con otros, la capacidad de empatizar y de tener esperanza en el futuro. Este autor da cuenta del importante impacto que la violencia tiene sobre la sociedad y cómo éste se cristaliza en cada persona, produciendo efectos no uniformes o comunes, los que dependen de la vivencia particular de cada individuo. El trauma psicosocial debe ser entendido como un proceso histórico que perturba las relaciones sociales, lo que se manifiesta en procesos psicosociales que tienden a la instauración de la desconfianza, el silencio y la violencia como formas de resolución de conflictos.

Estudios con sobrevivientes del genocidio armenio durante la Primera Guerra Mundial (Altounian, 2008; Kupelian, Kalayjian y Kassabian, 1998) y del genocidio en Camboya durante el régimen de Pol Pot (Kinzie, Boehnlein y Sack, 1998); con segundas generaciones de sobrevivientes japoneses de la bomba atómica (Tatara, 1998), con descendientes de sobrevivientes judíos del Holocausto (Barocas y Barocas, 1973; Lev-Wiesel, 2007; Rowland-Klein, 2004), con familiares de víctimas de las dictaduras en Chile (Becker y Díaz, 1998; Biedermann, 1991; Brinkmann et al., 2009; Díaz, 1991 y 1995), en Argentina (Edelman et al., 1998; Bekerman, Soutric, Pezet, Mazur, Oberti y Lagos, 2009), en Brasil (Cardoso, Calhau, Knijnik, Kolker y Vital, 2009) y Uruguay (Scapusio el al., 2009), dan cuenta que las situaciones traumáticas tienen consecuencias sobre varias generaciones de descendientes.

Una revisión de la literatura sugiere que hay diferentes términos que describen la transmisión del trauma. Albeck (1993) propone hablar de aspectos intergeneracionales del trauma; Danieli (1998) trabaja con el concepto legado multigeneracional del trauma; y Volkan (1996), usando principios freudianos, acuñó el término transmisión transgeneracional del trauma.

Desde los desarrollos teóricos de la psicología, el enfoque psicoanalítico y el enfoque sistémico aportan elementos clave para la comprensión de los procesos de transmisión transgeneracional de las experiencias traumáticas. Ambos enfoques entregan fundamentos teóricos que respaldan la idea que experiencias traumáticas marcan el tipo de relaciones familiares que se establecen entre los sobrevivientes.

El enfoque psicoanalítico clásico (Abraham y Torok, 1978/2005; Breuer y Freud, 1893) da cuenta del proceso de transmisión de las experiencias traumáticas a través de mecanismos intrapsíquicos. Freud señaló que cada individuo se divide entre dos necesidades, "ser uno mismo su propio fin y ser el eslabón de una cadena a la que se está sujeto, sin la participación de su voluntad" (Freud, 1914, p. 20). Para él, la continuidad transgeneracional se da en dos instancias psíquicas, el superyó y el ideal del yo, las que se constituyen en los niños a partir de los modelos respectivos de superyó e ideal del yo de sus padres. A través de estas instancias psíquicas, los padres pueden mantener a sus hijos como herederos de sus deseos, tanto prácticos como los de sus propias inhibiciones y tabúes (Tisseron, 1995/2001). 
La investigación sobre transmisión psíquica, sin embargo, fue ignorada durante largo tiempo por los psicoanalistas, quienes estaban más interesados en el determinismo intrapsíquico del inconsciente. El tema de la transmisión psíquica fue reabierto por la labor de Nicolás Abraham y María Torok entre los años 1961 y 1975, sobre el duelo, la "cripta" y el "fantasma". Un importante aporte de estos autores fue diferenciar entre las influencias intergeneracionales y transgeneracionales. La transmisión intergeneracional se produce entre las generaciones contiguas que presentan una relación directa, en cambio la transmisión transgeneracional se produce entre generaciones sucesivas. Así, el contenido emocional de los niños puede verse afectado por el funcionamiento psíquico de los abuelos aunque ellos no los hayan conocido, pero cuya vida psíquica está marcada por la de sus padres (Tisseron, 1995/2001).

La propuesta psicoanalítica clásica es consistente con la idea de una mente aislada, concepción que es enriquecida por los teóricos intersubjetivos (Stolorow y Atwood, 2004) y los teóricos sistémicos (Boszormenyi-Nagy y Spark, 2003; Lev-Wielse, 2007), quienes dan cuenta del proceso de transmisión de experiencias traumáticas mediante mecanismos que emergen de la interacción recíproca de los miembros de un sistema familiar. Lev-Wielse (2007) señala que los desarrollos teóricos de transmisión transgeneracional desde perspectivas sistémicas han hecho hincapié en dos procesos distintos en el desarrollo familiar: patrones familiares multigeneracionales, y procesos y eventos del ciclo de vida familiar. En esta misma línea, Boszormenyi-Nagy y Spark (2003) sostienen que ciertas pautas relacionales se transmiten a los miembros de la familia a través de la lealtad y el endeudamiento de unos a otros, indicando la existencia de tramas de lealtades invisibles en las familias que implican la existencia de expectativas estructuradas de grupo, en relación con las cuales todos los miembros adquieren un compromiso, moldeando y dirigiendo el comportamiento individual.

En Chile, los profesionales del Instituto Latinoamericano de Derechos Humanos y Salud Mental (ILAS), del Centro de Salud Mental y Derechos Humanos (CINTRAS) y de la Corporación de Promoción y Defensa de los Derechos del Pueblo (CODEPU), dedicados a la atención de víctimas de violencia política, estudiaron el fenómeno de la transmisión transgeneracional del trauma psicosocial en la segunda generación: hijos de perseguidos políticos durante la dictadura militar. Becker y Díaz (1998), Biedermann (1991), Brinkmann et al. (2009), Faúndez et al. (1991) y Díaz (1995), utilizando los aportes del enfoque sistémico y psicoanalítico, coinciden en señalar que el trauma se incorpora en un tipo de dinámica relacional que dificulta el proceso de individuación y formación de la identidad de los hijos. Los hijos de familias afectadas han sido y siguen siendo confrontados con una serie de mandatos, expectativas y legados que impactan directamente en la realización de sus proyectos de vida. Las familias no pueden tolerar la individuación en los hijos adolescentes porque ésta reedita los sentimientos de pérdida y duelo no elaborados.

En la actualidad, en Chile no existen estudios de transmisión del trauma con terceras generaciones. Sin embargo, a 40 años de ocurrido el golpe de Estado es posible sostener la existencia de un gran número de nietos de víctimas de violencia política, cuyas vidas están marcadas por la experiencia del trauma psicosocial (Faúndez y Cornejo, 2010). Según el Informe de la CNPPT (2004), del total de casos calificados, el 40.1\% (10.938) corresponde a personas que el año 2004 tenían entre 51 y 60 años de edad, mientras que el 42.9\% (11.697) tenía más de 60 años. Si consideramos estos antecedentes es posible afirmar que en la actualidad la mayor parte de los ex presos políticos (en adelante ExPP) superan los 70 años. Coherentemente con estos datos, la base estadística del Fondo Nacional de Salud (FONASA), en 2012, registró un total de 650.000 beneficiarios del Programa de Reparación y Atención Integral de Salud y Derechos Humanos (PRAIS) ${ }^{1}$, de los cuales un tercio corresponde a personas menores de 20 años (P. Godoy ${ }^{2}$, comunicación personal, agosto 17, 2012), quienes comparten la condición de hijos o nietos de víctimas de violencia política. Todos estos antecedentes confirman la pertinencia de realizar estudios a nivel nacional sobre la transgeneracionalidad del trauma producto de la violencia política con terceras generaciones.

A nivel internacional, cada vez hay más evidencia acerca de la transmisión de los traumas psicosociales a la tercera generación. La mayor parte de los estudios ha sido desarrollada en Israel (Chaitin, 2000). También se ha hecho investigación con la tercera generación en Alemania (Rosenthal, 1998), en España (Miñarro y Morandi, 2009) y en Estados Unidos (Bender, 2004). Los resultados de estos estudios concuerdan que las experiencias traumáticas,

\footnotetext{
El Programa de Reparación y Atención Integral de Salud y Derechos Humanos (PRAIS), es la respuesta del Ministerio de Salud chileno al compromiso de reparación de las víctimas de violaciones a los derechos humanos entre septiembre de 1973 y marzo de 1990. Este programa se sustenta ética y legalmente en las recomendaciones de la Comisión Nacional de Verdad y Reconciliación, en la Ley 19.123 de Reparación y Reconciliación, en las Leyes 19.234 y 19.582 de Exonerados Políticos y en la Ley de Retornados.

2 Paula Godoy, encargada nacional del Programa PRAIS, perteneciente a la Subsecretaría de Redes Asistenciales del Ministerio de Salud de Chile.
} 
provocadas por violencia política, se transmiten a través de las generaciones. Las dinámicas de evitación y silencio en torno a la experiencia traumática caracterizan las relaciones al interior de las familias de las víctimas, determinando la relación de los nietos con la experiencia traumática.

\section{Método}

La investigación utilizó metodología cualitativa (Cornejo, Besoaín y Mendoza, 2011; Sandoval, 2013; Vasilachis de Gialdino, 2009) desde un diseño exploratorio -debido a la escasez de trabajos en Chile sobre este tema- y analíticorelacional-intentando construir un modelo comprensivo del fenómeno-. Se inscribe además en el enfoque biográfico (Cornejo, 2006; Legrand, 1993), ya que se comprende, las historias personales influidas y articuladas a las historias familiares y sociales, considerando las narraciones como vías de acceso privilegiadas para la construcción de conocimiento relevante respecto a ciertas temáticas.

\section{Participantes}

Participaron catorce nietos de ExPP de la dictadura militar chilena, ocho mujeres y seis hombres, con un promedio de 21.4 años de edad. Todos los nietos son de nivel socio-económico medio, con un promedio de 14 años de escolaridad. Ocho nietos provienen de la región Metropolitana y seis de la región de La Araucanía (dos de los cuales se identifican como mapuche, pueblo originario de Latinoamérica que habita el sur de Chile y el suroeste de Argentina).

Respecto a los abuelos/as que sufrieron PPT: en 10 casos era un abuelo; en un caso una abuela; y en tres casos más de un abuelo y/o abuela, formando un total de 19 abuelos/ abuelas ExPP. Del total de abuelos ExPP, cuatro habían fallecido, dos de ellos antes que el nieto naciera. En todos los casos, el abuelo ExPP o algún otro miembro de la familia participaba de una agrupación de derechos humanos.

\section{Instrumento}

Para la producción de datos se hicieron relatos de vida, entendidos como la enunciación oral por parte de un narrador de su vida o una parte de ella (Cornejo, 2006; Cornejo, Mendoza y Rojas, 2008). Se utilizó una consigna inicial común con todos los participantes para la construcción de sus relatos: "Cuéntame tu historia de vida como nieto/a de una persona que sufrió prisión política, durante la dictadura militar chilena". Esta opción metodológica se orientó a intencionar la construcción de historias de vida de los jóvenes, que permitiera articular su propia historia con la de PPT del o los abuelos.

Los relatos se realizaron a lo largo de tres encuentros con cada participante, los que duraron entre una hora y una hora y media cada uno. Todos los encuentros fueron llevados a cabo por la investigadora, de acuerdo a criterios de no-directividad, una escucha cálida y una comprensión empática (Cornejo et al., 2008).

\section{Procedimiento}

El reclutamiento de los participantes se realizó a partir de informantes clave pertenecientes a agrupaciones de ExPP y derechos humanos, quienes proporcionaron datos de ExPP que tuviesen nietos de entre 18 y 25 años de edad. Los ExPP contactados por la investigadora, a su vez, entregaron nombres y números de teléfonos de nietos que habían manifestado interés en participar en el estudio. Finalmente, los nietos fueron contactados directamente e invitados a participar en el estudio.

En total se contactó a 19 nietos, a quienes se les presentó el estudio y las características de su participación; de ellos, 14 aceptaron participar, con los cuales se realizó un proceso de consentimiento informado asegurando la libertad de su participación, la posibilidad de retirarse cuando lo estimaran pertinente, así como la confidencialidad de la información entregada y la mantención del anonimato de sus identidades. Se les solicitó además autorización para grabar los encuentros.

Los encuentros se realizaron en lugares, fechas y horarios determinados por cada participante, con intervalos de entre 15 y 20 días. Todos los relatos fueron entre mayo de 2010 y enero de 2011.

Los relatos fueron transcritos integralmente, eliminándose datos de identificación e intentando conservar las fallas en el lenguaje, vacilaciones, uso de lenguaje corriente, pausas, interrupciones, silencios, risas y cualquier otro dato posible de consignar y que otorgara información acerca del proceso de co-construcción dialógica del relato (Roulston, Marrais y Lewis, 2003).

Considerando el tema sensible (Lee, 1993), así como el carácter dialógico y contextual del relato de vida, se optó por integrar las condiciones de los relatos en la producción, análisis e interpretación de éstos (Cornejo, 2008; Cornejo et al., 2008). Se desarrollaron tres dispositivos de escucha (Cornejo et al., 2011) para considerar la subjetividad de la interacción investigador-participante: cuaderno reflexivo de la investigadora (registro de las reflexiones de la investigadora 
durante el proceso de producción y análisis de los relatos); notas de campo del transcriptor (reflexiones de los transcriptores a partir de la escucha y transcripción de los relatos, respecto al contenido y la forma de la historia relatada); y proceso de interanálisis (Legrand, 1999), instancias grupales para trabajar aspectos transferenciales y contra-transferenciales presentes en la relación de interlocución entre investigadora y participante. Todos estos dispositivos permitieron una discusión crítica acerca del relato y la historia narrada en los encuentros con cada participante, otorgando nuevos puntos de vista a los análisis.

\section{Análisis de datos}

Para el relato de cada participante se implementó un análisis en dos etapas: singular y transversal (Cornejo et al., 2008). En la primera se analizó multidimensionalmente cada caso utilizando una pauta de análisis singular (Faúndez, 2013) construida especialmente y basada en contribuciones de la teoría de la interpretación de Ricœurn (1995), del análisis narrativo (Cornejo, 2008; Rosenthal, 1998) y del análisis del discurso (Jofré, 1990; Van Dijk, 1978). Se construyó para cada participante un informe del análisis de sus relatos a partir de la información proveniente de todas las etapas del proceso -contacto, producción, transcripción-, lo que dio un espesor analítico y una mayor densidad a sus análisis (Cornejo y Salas, 2011).

La etapa transversal consistió en un análisis de los informes singulares de cada caso, realizando un proceso de conceptualización, reducción y articulación de los datos a partir de los procedimientos propuestos por la grounded theory (Glaser y Strauss, 1967; Strauss y Corbin, 2002), lo que determinó construir ejes e hipótesis transversales sobre el fenómeno en estudio.

\section{Resultados}

A continuación se presentan parte de los resultados del estudio. Éstos están organizados en torno a una de las dimensiones abordadas por el estudio mayor. Específicamente, en este artículo se muestran las características de la narración de la historia de vida de los nietos de ExPP. Esta dimensión aborda la forma específica en que los relatos de vida fueron construidos por los participantes del estudio, análisis que permitió un primer acercamiento a las particularidades de los procesos de transmisión y apropiación de la historia de PPT. Por lo anterior, la caracterización de los relatos se presenta como eje introductorio de los resultados.
Cabe señalar que en un trabajo anterior (Faúndez, Brackelaire y Cornejo, 2013) se presenta una dimensión complementaria a lo tratado en el presente artículo, asociada a la detención del abuelo como el evento de origen de la historia traumática de PPT. Se plantea que la detención del abuelo emerge en los relatos de vida como un evento dañino que da origen a la historia familiar traumática. Los narradores interpretan la ocurrencia de este hecho como provocador de un quiebre inesperado en la historia familiar; se trata de un evento que aniquila la posibilidad de desarrollo y continuidad de la vida del abuelo, lo que causa un impacto directo en la historia familiar.

A continuación se presenta una caracterización detallada de los relatos de vida de los nietos de ExPP desarrollada en base a las dimensiones que emergieron durante la producción y análisis de estos relatos.

\section{La constitución del nieto de ExPP como narrador de la historia familiar traumática}

Tras el inicio de los procesos de construcción de los relatos de vida, fue necesario un proceso de ajuste en la relación participante-investigadora, que permitiera la constitución de los roles de narrador -hablante, autor del relato- y narratoria -se utiliza este término por ser la traducción de narrataire, definido por De Villers (1996) como aquella persona que escucha el relato-. En este proceso, los nietos interpelaron constantemente a la investigadora consultándole acerca del valor y utilidad de sus relatos, por lo que ésta debió pronunciarse al respecto, reconociéndolos y legitimándolos en dicho rol. A su vez, la investigadora, a través de una escucha empática y una participación comprometida, fue asumiendo gradualmente el lugar de interlocutora legítima, es decir, de alguien confiable y capaz de acompañarlos en la construcción de sus historias.

Así, la constitución de los roles de narrador y narrataria fue el resultado de un acuerdo entre participante e investigadora, lo cual no solo involucró el cumplimiento formal de las exigencias éticas de toda investigación, sino que exigió un compromiso implícito entre cada nieto y la investigadora, que se dio a partir de las primeras interacciones y que les permitió legitimarse como interlocutores confiables.

Durante los primeros contactos telefónicos, así como al inicio de los primeros encuentros, algunos nietos expresaron sus dudas sobre la utilidad y valor de su participación en el estudio. Ellos argumentaron que no habían nacido cuando su abuelo fue detenido y que, por lo tanto, no eran los miembros de la familia más indicados para narrar dicha experiencia. Frente a esto, la investigadora respondía confirmando su 
interés por conocer la historia de PPT desde la perspectiva de los nietos, invitándolos a asumir el rol de narradores. Esto se evidencia en las notas del cuaderno reflexivo de la investigadora $(\mathrm{CRI})$ :

“...Nuevamente llamo por teléfono a casa de Galvarino y esta vez me responde él. Me presento, le hablo del estudio y lo invito a participar. La voz del joven se escucha un tanto incómoda, dubitativa. Me señala que estudia en la universidad y que no sabe si tendrá tiempo, además agrega que duda que su relato sea de utilidad, ya que él no había nacido cuando su abuelo fue detenido. Le pido que lo piense más, que me interesa mucho que acepte participar, que me interesa su relato desde la perspectiva de nieto y que los encuentros pueden realizarse en el lugar y a la hora que más le convengan. Acordamos que en unos días lo volveré a llamar por teléfono" (Galvarino, CRI, E2, $1^{3}$ ).

Frente a la solicitud de contar su historia, los nietos respondieron de dos formas, dependiendo de la relación que mantenían con sus abuelos. Un primer grupo de nietos reconoció mantener una buena relación con su abuelo ExPP, caracterizada por una cercanía física y afectiva. En muchos casos los nietos viven o han vivido con sus abuelos o se visitan constantemente, compartiendo con ellos momentos importantes de sus vidas. Los miembros de este grupo se posicionaron rápidamente en el lugar desde donde la investigadora les invitaba a hablar. Los jóvenes se presentaron, desde el inicio del relato, como un nieto o una nieta de uno o más ExPP de la dictadura militar chilena.

"Perfecto. Ya, ya bueno, primero, yo soy nieta de cuatro, o sea, todos mis abuelos son ex presos políticos y torturados, siempre he estado con esta historia y siempre en el medio de lo que es la política..." (Patricia, E1, 2).

Dentro de este primer grupo, algunos participantes iniciaron sus relatos identificándose como nietos de ExPP a través de sus nombres y apellidos. En estos casos, los apellidos de los nietos coinciden con los de sus abuelos ExPP, lo que podría ayudarlos a presentarse como testimoniantes de la historia familiar. Esta presentación posicionó

\footnotetext{
Se incluirán viñetas correspondientes a citas textuales provenientes de los relatos de vida (E) y de los cuadernos reflexivos de la investigadora (CRI). Serán identificadas con el pseudónimo del participante, el número del encuentro (E1, E2 y E3) y el número del párrafo. Todos los nombres de personas y lugares incluidos en las viñetas son ficticios.
}

a los nietos en un lugar especial para iniciar el relato. Ellos son los descendientes consanguíneos de sus abuelos y los herederos legítimos de la historia familiar, condición que les permite comenzar a reconocerse como una voz autorizada para hablar de dicha historia.

“Bueno, mi nombre es Valeska Ana Gómez Yáñez, soy
nieta de Miguel José Gómez Zapata, mi abuelo fue preso
político, fue torturado” (Valeska, E1, 4).

"Eh, bueno, yo me llamo, bueno, buenos días, eh, yo me llamo Eduardo Fabián Rodríguez Cevallos, eh, igual que mi abuelo, que fue preso político..." (Eduardo, E1, 4).

Un segundo grupo de nietos recorre un camino distinto en la construcción inicial de sus relatos de vida, comenzando sus historias contextualizando la relación actual que tienen con sus abuelos. En general, los nietos de este grupo declaran mantener una relación más distante con el abuelo víctima de PPT, debido a que viven lejos de éste o ha fallecido.

“...para partir, yo no conocía ninguno de, de mis dos abuelos, porque mi abuelo eh, murió en el '75 y bueno, el materno, y por el lado de, de mi de mi papá em, nunca lo conocí. Así que en realidad de abuelo, yo no tengo ninguna, por decir, afinidad. Nunca he tenido un abuelo" (Alejandro, E1, 4).

Los nietos de este grupo parecen tener la necesidad de justificarse antes de comenzar a contar su historia, posicionándose como personas que reconocen la existencia de la historia familiar de PPT, pero anticipando el desconocimiento de los detalles de esta experiencia. Esto puede relacionarse directamente con la distancia física y/o emocional que dicen mantener con sus abuelos, lo cual sin duda produjo menos oportunidades para conocer la historia de PPT a partir de la versión de los propios protagonistas, generando una menor identificación de los nietos con esta historia. Pero también es posible plantear que la distancia con los abuelos se puede relacionar con el mayor silencio mantenido por éstos respecto a la experiencia traumática. Silencio debido a los límites psicológicos, descritos por los teóricos psicoanalistas (Kaës, 2006; Puget, 2006), para pensar y representar dichas experiencias, así como a la imposición del silencio al interior de las familias, debido al temor de daño que dicho recuerdo pudiera llegar a producir (Danieli, 1998).

“... a mí nunca me lo dijeron cuando yo era chica. [...] hasta que... no sé, me recuerdo una vez que tendría 
no sé, como diez años, y mi papá como que habló del tema conmigo [...] Entonces como que ellos nunca nos habian contado nada al respecto hasta que tuve como diez años y mi papá una vez me contó. Ehm, que a mi abuelo lo habian detenido... Yo, mayores detalles de lo que pasó, aparte de que lo detuvieron en reiteradas ocasiones, no sé” (Millaray, E1, 126-127).

En síntesis, el análisis de la forma en que los relatos de vida fueron iniciados permite plantear que los nietos adoptaron dos estrategias narrativas. Un primer grupo se posicionó rápidamente en el lugar desde donde la investigadora les invitaba a hablar, esto es, como un nieto o una nieta de uno o más ExPP de la dictadura militar chilena. A su vez, un segundo grupo recorrió un camino distinto en la construcción inicial de sus relatos de vida, contextualizando la relación actual que tienen con sus abuelos. Sin embargo, independiente de la manera en que los participantes comenzaron sus relatos, todos se mostraron dispuestos a construir su historia de vida como nietos de ExPP. Los nietos mostraron una motivación para indagar en sus historias personales y buscar la conexión de ésta con la historia familiar y social.

La invitación a participar en el estudio actuó como una interpelación para los participantes que los llevó a posicionarse progresivamente, dentro de la trama discursiva, como narradores de la historia de PPT familiar referida a las experiencias de sus abuelos, reproduciendo, modificando y creando significados en torno a esta experiencia. La posición del narrador se refiere a la actitud de mayor o menor cercanía que el hablante tiene para con la historia que narra (Jofré, 1990). Durante la construcción de los relatos de vida, cada nieto presentó diversas posiciones respecto a la historia narrada. Tanto al inicio como a medida que avanzaban en la construcción de sus relatos a través de los encuentros con la investigadora, los participantes variaron sus posiciones, alcanzando progresivamente una mayor cercanía con la historia contada. Este proceso se dio de manera distinta entre los nietos, quienes asumieron y variaron sus posiciones frente a la historia narrada en distintos momentos de los encuentros, no existiendo un patrón único ni estable, ni tampoco una relación directa entre la posición del narrador y un único encuentro.

El proceso de construcción de los relatos de vida constó de tres momentos con características distintas: el inicio del relato, asociado al primer encuentro, en que predominó la posición del narrador testigo; el desarrollo del relato, que se extiende entre el primer y segundo encuentro y en que predominó la posición del narrador involucrado; y el cierre del relato, asociado al último encuentro y en que predominó la posición del narrador protagonista. Cada una de estas etapas posee características propias y distintivas en relación a las posiciones asumidas por los narradores, las que se detallarán a continuación.

\section{a. Etapa 1, el inicio del relato: El narrador testigo}

En esta etapa, los nietos narran una historia pretérita, una historia que les es lejana, que pertenece a sus padres y abuelos. Es una historia heredada, que han reconstruido a partir de historias y silencios familiares.

"Por lo que me contaron a mí, a mi abuelo lo fueron a buscar cuando él vivía en el campo, arriba, lo fueron a buscar los milicos y lo bajaron... a punta de patás, como se dice..." (Jorge, E1, 6).

En la narración predomina insistentemente el uso de la tercera persona -él, ellos-, lo que se relaciona con que se cuenta una historia de otros. Los protagonistas de la historia son las víctimas que sufrieron de forma sorpresiva e injustificada un trato coactivo y la transgresión de sus derechos por parte de sus victimarios. Se describe el allanamiento del domicilio familiar, el secuestro en la vía pública, la detención con violencia y posterior prisión política. Estas descripciones revelan la desigualdad de poder entre víctimas y victimarios: los abuelos son descritos por los nietos como ciudadanos que se encuentran desarmados y que generalmente son detenidos en sus casas, frente a sus esposas e hijos pequeños; y los agentes del Estado, quienes siempre se movilizan en grupos y fuertemente armados.

En esta etapa del relato prevalece la descripción testimonial de los hechos, en el sentido descrito por Morales (2001), ya que los nietos, al reconstruir este evento y denunciar el sufrimiento experimentado por las víctimas, construyen un discurso en el cual no solo ponen en evidencia las relaciones de poder asociadas a la violencia política, sino que hablan en nombre de las víctimas de PPT. Los nietos parecen ofrecer su testimonio al igual que un testigo o tercero que denuncia un delito en un proceso judicial entre dos contendientes. Se esfuerzan por limitarse a declarar "lo sucedido", evitando realizar interpretaciones en relación al impacto afectivo que significa para ellos que los protagonistas de la historia contada sean sus propios abuelos.

"Ehm, estaban en un día normal en la casa, cierto, todos en la casa [...] Y, y, según lo que me cuenta mi abuelo, y todos mis tíos, eh, llegó personal militar ¿Ya? Yobviamente se llevaron, tomaron detenido a mi abuelo, 
Eugenio Huerta, y en verdad nadie entendía el por qué, solamente se lo llevaron" (Jenny, E1, 10-12).

Pese a las dudas iniciales sobre la utilidad de su relato para los objetivos del estudio, los nietos, sin distinción respecto al tipo de relación que mantienen con sus abuelos en la actualidad, construyen sus relatos manifestando un alto grado de conocimiento, dando cuenta que poseen antecedentes suficientes para reconstruir "la historia de PPT de su abuelo". En sus relatos integran parámetros espaciales y temporales de la historia familiar vinculados con este hecho, aportando datos sobre lugares y fechas en que ocurren los acontecimientos relatados, los cuales parecen ser incorporados por los nietos para reforzar la veracidad de sus relatos. Estos antecedentes son articulados, a medida que avanzan los relatos de vida, con interpretaciones, emociones y la historia personal de los nietos.

\section{b. Etapa 2, el desarrollo del relato: El narrador involucrado}

A medida que los nietos avanzan en la construcción de los relatos, la búsqueda de neutralidad, propia de un testigo que narra a otro los hechos trágicos del pasado de un tercero, comienza a desaparecer los nietos empiezan a asumir una posición en que se involucran emocionalmente con la historia que cuentan. Comienzan a integrar interpretaciones y comentarios subjetivos, expresan sus opiniones $\mathrm{y}$ emociones respecto de la historia que les han contado y que ellos ahora reconstruyen.

Algunos nietos rompen con el silencio de sus abuelos y familias, denunciando la ocurrencia de la tortura. Ésta se cuenta como un hecho del cual no hay pruebas ni testigos ya que los abuelos ExPP son los únicos capaces de confirmar su ocurrencia y generalmente éstos la han mantenido el silencio. En los casos en que los abuelos han hablado de la tortura, nunca han logrado expresar la experiencia propiamente tal, lo pensado, lo sentido durante la tortura.

"Y no voy a suponer de que no le hicieron nada, o sea, obvio que lo, que lo torturaron, pero él cuando llegó no, nunca habló con nadie. Y mi abuela me ha dicho que él nunca, que él llegó distinto, mi abuelo era un persona que, que hablaba mucho, que era muy cariñoso, pero cuando él llegó nunca dijo nada sobre lo que le hicieron y sus amigos, nunca nadie, que siguen vivos, nunca nadie ha dicho sobre por lo, sobre lo que pasó, sobre lo que pasó ahí, así que sobre de detalles eh, sobre los detalles de tortura, o qué realmente le pasó ahi" (Alejandro, E1, 22).

Mientras que la mayoría de los nietos nunca han escuchado a sus abuelos referirse directamente a la experiencia de tortura, para llegar a la convicción de que fueron víctimas de tortura pareciera que no basta la información recibida de la familia respecto a dicha experiencia, ya que los nietos señalan haber buscado, activamente, información que les permita confirmar lo ocurrido.

"Como tenía tanta curiosidad, mi abuelo tenía un libro que se llama algo del, no sé si el Valech ${ }^{4}$ o Rettigs. No sé, pero es un libro más o menos como monstruoso. Y un día yo, yo pasaba [...] del colegio me pasaba al negocio porque ahi tenía una mesa para estudiar tranquilamente. Yo una vez me acerco a ese libro [...] Me acerco a ese libro y me lo puse a leer. Y pero cuando leo trato de imaginarme las cosas, y lei puras, puras atrocidades [...] Y también busqué la lista de todos los torturados y salía el apellido de mi abuelo, o sea, salía el apellido de mi abuelo, no sé si el nombre, no recuerdo, pero salía el rut de mi abuelo y el nombre también" (Eduardo, E1, 147-151).

A medida que desarrollan sus relatos, los nietos expresan las emociones que la historia familiar les provoca, dando cuenta principalmente del dolor y la rabia asociados a ésta, lo que demuestra los efectos directos de la PPT en sus familias. Entre las consecuencias señaladas por los nietos se encuentran las secuelas físicas y psicológicas en los abuelos ExPP y las secuelas psicosociales en la familia. Muchos ExPP sufrieron cesantías prolongadas, experiencia que truncó las posibilidades de que los hijos continuaran sus estudios, debiendo éstos adelantar su ingreso al mundo del trabajo.Algunos nietos señalan que tras la experiencia de PPT sufrida por sus abuelos, sus padres, quienes eran niños o jóvenes en esa época, tenían temor que sus padres o algún

\footnotetext{
4 Informe Valech, nombre con que es conocido en Chile el informe entregado por la Comisión Nacional sobre Prisión Política y Tortura en 2004. La comisión fue presidida por monseñor Sergio Valech, razón por la cual se le conoce popularmente como Informe Valech. El informe reúne los casos de quienes voluntariamente fueron a declarar ante dicha comisión y fueron calificados como víctimas de prisión política y tortura durante la dictadura militar de Augusto Pinochet.

5 Informe Rettig, nombre con que es conocido en Chile el informe entregado el 9 de febrero de 1991, por la Comisión Nacional de Verdad y Reconciliación, sobre las violaciones a los derechos humanos acaecidas en Chile durante la dictadura militar de Augusto Pinochet. Raúl Rettig presidió la comisión, razón por la cual se le conoce popularmente como Informe Rettig.
} 
otro miembro de la familia fuese dañado nuevamente debido a su compromiso político o su participación en movimientos sociales. Se trata de una emoción que es consistente con el contexto social de la dictadura militar en Chile (Lira y Castillo, 1991), pero que en algunos casos se mantiene en el tiempo y se reactiva en la actualidad frente al actuar o compromiso social y político de los propios nietos. La existencia de una amenaza real de muerte y el sentimiento de vulnerabilidad e impunidad de los crímenes cometidos en dictadura generan en algunos hijos de ExPP un rol pasivo, temeroso de la participación política y de la denuncia de las violaciones a los DD.HH. Los nietos justifican esta conducta, interpretándola como una respuesta adaptativa a la época que les tocó vivir a sus padres.

La expresión emocional se evidencia tanto en el contenido como en la forma que adquiere el relato al hablar sobre la tortura. Como sucede en todo proceso socio-comunicativo, en la construcción de los relatos, la expresión emocional entregó información que permitió a la investigadora desarrollar una escucha empática y una respuesta emocional adecuada. Las expresiones emocionales también se evidenciaron a través de cambios en la postura corporal de los narradores, quienes realizaron movimientos que parecían ayudarlos a controlar el desborde emocional: se tocaban la cara, agachaban la cabeza, se abrazaban las piernas.

El dolor es una emoción que se manifiesta y actualiza en los encuentros con la investigadora al intentar dimensionar las secuelas físicas y psicológicas que dejó la tortura, no solo en sus abuelos sino también en sus padres. Los narradores afirman que el dolor es compartido con los demás miembros de la familia. Se trata de una emoción que los vincula y distingue como miembros de una familia afectada por la experiencia de PPT. Esta emoción se manifiesta con miradas, gestos, llantos y silencios al interior de la familia, el dolor se transmite en la relación familiar y se actualiza cada vez que se intenta hablar del tema.

"Eh, no poh, lo que te contaba de, de, de que no habla del tema, lo vivió y todos sabemos que lo vivió, pero nunca lo ha tocado. Y cuando le preguntamos lo cambia, y cuando le preguntamos baja al tiro la mirada como que no, tiene uno le nota cuando lo ve que aquí tiene algo, así en el pecho algo le acongoja con respecto a ese tema..." (Andrea, E1, 59).

Los nietos también expresan sentir rabia por la experiencia de tortura sufrida por sus abuelos, emoción que se canaliza hacia la figura del torturador. así tortura y torturador se presentan como conceptos irracionales y exigen, por parte de los nietos, esfuerzos de comprensión. Éstos se cuestionan acerca de los límites de la conducta humana, se preguntan sin lograr responderse ¿cómo un ser humano es capaz de torturar a otro ser humano?

"Eh, a veces, a veces me da como rabia [...] ;Me da rabia! Si poh, me da rabia porque no nunca eh, nunca he visto personas tan cobardes. Cómo, cómo llegar a, cómo ser tan miserable, cómo ser tan, tan, despreciar tanto al, a los derechos humanos, a la misma persona, siendo que muchos de ellos fueron obligados, fueron obligados pero muchos, muchos de ellos también lo disfrutaron..." (Alejandro, E2, 79-81).

Mediante la construcción de su relato de vida, los nietos instalan la historia familiar de PPT en el tejido social, califican la detención de sus abuelos como un hecho injusto cometido en un contexto histórico social caracterizado por la violación sistemática de los DD.HH., contexto en que sus abuelos sufrieron al igual que muchos otros chilenos. Esto puede deberse a que, como señala De Gaujelac (1987) la narración de la historia de vida permite la integración de la experiencia como unidad de sentido; el relato funde pasado, presente y futuro, permitiendo reconstruir y reelaborar de otro modo eso que ha sido vivido o transmitido anteriormente, dándole sentido a algo que antes lo carecía.

"Es que yo cuando contaba historias contaba la de mi abuelo, pero quizás como la de mi abuelo hubieron muchas, entonces, estaba contando historias de mucha gente al fin y al cabo. Y al no tomarle el peso a la de mi abuelo, ni siquiera, si no le tomaba el peso a la historia de mi abuelo, imagínese, que es mi familiar, menos se la iba a tomar a otra gente. Entonces ahora, tampoco por falta de respeto, es que eso es lo que no quiero que se mal interprete, que soy respetuoso con la gente que sufrió. A lo que voy es a que yo no la contaba con intensión, digamos, de seriedad, de rigurosidad del tema, porque es un tema grave poh, son los derechos humanos de las personas" (Eduardo, E3, 32).

En esta etapa, los nietos también entregan sus opiniones respecto a la PPT. Esta experiencia, por ejemplo, es comparada y evaluada por algunos de ellos como similar con las formas de violencia política que, actualmente, ejerce el Estado de Chile contra el pueblo mapuche o contra los estudiantes que se manifiestan públicamente. Esta relación, construida en el relato, entre la violencia política del pasado y la violencia política del presente, entrega un nuevo 
sentido a la experiencia de PPT, basado en la desigualdad de derechos de los ciudadanos frente al Estado y la repetición de los ciclos de violencia en la historia de Chile, dirigida siempre hacia los más vulnerables de la sociedad.

"Qué siento... Eh... también me da rabia por todo lo que tuvieron que pasar, sufrieron bastante, eh, no sé, encuentro que es injusto, y que todavía siguen sucediendo cosas injustas con los mapuches o con los estudiantes, con toda la gente... eh no sé, me da rabia que siga... no sé, una sociedad de esa manera, que ha cambiado bastante poco en tanto tiempo" (Mauricio, E1, 109).

Así, para los nietos de ExPP mapuche, la experiencia de PPT sufrida por sus abuelos se encuentra inserta en el marco del despojo y de la violencia ejercida históricamente contra el pueblo mapuche por el Estado chileno. En este contexto, la experiencia de PPT tiene para estos nietos una carga de discriminación social distinta a la de los presos políticos no mapuche, siendo calificada literalmente por ellos como un "doble atropello". Los nietos sostienen que durante la dictadura militar se atropellaron los derechos del preso político mapuche tanto por opción ideológica como por su origen étnico y socio-cultural vulnerable.

“...en cierta medida lo veo como casi un doble atropello, por decirlo así, por darle una denominación. Ehm y no por eso vamos a decir que, por ejemplo, el hecho de que mi abuelo haya sido preso es más terrible que una persona común haya sido, porque pienso que igual es terrible, pero a lo que voy es que, pienso que, que él. A ver, la posición que tenía mi abuelo, en la sociedad o, o sí, dentro de su entorno social, era mucho más frágil que la de otras personas" (Millaray, E2, 111).

Finalmente, cabe señalar que los nietos también expresan su opinión respecto a lo que ellos califican como el silencio $\mathrm{e}$ indiferencia de la sociedad chilena frente al sufrimiento de sus familias durante la época de la dictadura militar. Los nietos intentan darle sentido a esta falta de empatía ante al horror de la tortura y el dolor de sus familias, desarrollándose explicaciones basadas en las diferencias sociales y de poder económico entre los chilenos, concluyendo que quienes tenían el poder económico en Chile vieron en la dictadura militar una forma de mantener a resguardo sus bienes y poder.

\section{c. Etapa 3, término del relato: El narrador protagonista}

En esta etapa predominó el uso de la primera persona singular, el yo, que permite a los nietos presentarse como protagonistas de la historia que narran, así como asumir posiciones personales frente a esta historia. Los nietos hablaron de su actuar político-social, de sus compromisos presentes y de proyecciones futuras. Algunos se presentaron como líderes comunitarios, sociales y/o políticos, poseedores de sus propios y actuales sentidos de lucha.

"Yo también tengo, yo pertenezco allá en [nombre de la comuna] a una agrupación, un movimiento social, en donde tengo compañeros que van desde que son comunistas, ;Más al extremo!, ellos dicen que son del Frente...hasta DC [...] Entonces yo pertenezco a esto desde el 2006, cuando yo tenía 16 años..." (Alejandro, E3, 217).

La elección profesional y ciertos proyectos de vida son interpretados por algunos nietos como conductas propias inspiradas en la historia de vida de sus abuelos, asociada a la lucha social. Ellos asumen la tarea de continuar un legado familiar que los identifica, vinculado al desarrollo de una sociedad más justa y solidaria.

“...él estaba ayudando a su gente, su gente que era igual de frágil que él. O sea que eran pobres, que no se podían comunicar, porque en el fondo lo que mi abuelo hacía era eso, como él sabía hablar castellano, hacía nexo entre las comunidades [mapuche] y la gente que trabajaba en el gobierno [...] Yo soy capaz de reflexionar dado que eso es un ejemplo de vida para continuar, me parece que, por lo mismo si yo quiero ayudar a determinados grupos, ehm, a... a no verse disminuidos en sus derechos, por ejemplo, a que no sean atropellados, yo necesito formarme, aprender la forma en cómo ellos quieren ser reconocidos en sus derechos y cómo yo, utilizando las herramientas que existen, puedo ayudarlos..." (Millaray, E2, 16-112).

Los nietos también se proyectan en la labor de continuar transmitiendo la historia de PPT a los miembros más jóvenes de la sociedad, tales como sus amigos, pares y futuras generaciones, con el objetivo de mantener viva la memoria familiar y evitar que se repitan los mismos hechos dolorosos en el futuro. 
"Yo después, cuando sea profe, también quiero crear consciencia en distintas situaciones, pero más en eso, por eso quiero ser profe también, porque uno se relaciona con tantas personas que es más posible informar y hacer como pensar, hacer click a la gente que no ve más allá que un computador, o la tele [...] estos pequeños detalles que son súper importantes, porque a partir de lo que uno pueda contar o lo que uno pueda traspasar a las demás personas pueden haber cambios sociales importantes para que no vuelvan a suceder estas cosas..." (Andrea, E2, 88; E3, 44).

En esta última etapa, los nietos de ExPP asumen la posición de narradores protagonistas de la historia que cuentan, presentándose como actores protagónicos de su historia $\mathrm{y}$, en algunos casos, presentándose incluso como agentes sociales de cambio. En esta etapa, los nietos muestran sus esfuerzos por integrar la experiencia de PPT de sus abuelos en su propia historia de vida, dando nuevos significados a la historia de éstos y, a pesar del daño y dolor asociados a esta historia, reflexionan acerca de la importancia de su testimonio en la actualidad.

Las etapas descritas facultan a los narradores a llegar al último encuentro asumiendo una relación que denominamos de apropiación de historia de PPT, la que implica que los nietos asumen la historia familiar como parte de su historia personal. Esto permite plantear que la historia de vida de los nietos de ExPP de la dictadura militar chilena se inscribe en una lógica de transmisión y apropiación transgeneracional del trauma psicosocial asociado a la memoria familiar respecto a la experiencia traumática de prisión política y tortura. Los nietos de ExPP chilenos, al igual que sus padres, se encuentran enfrentados a una historia o memoria familiar traumática que constituye en parte su propia identidad. Los nietos de ExPP han sido y siguen siendo confrontados con un pasado de sufrimientos e injusticias padecidas directamente por sus padres y abuelos; a la vez están confrontados con un discurso proveniente de la sociedad post dictatorial que, desde la perspectiva de los nietos, niega la experiencia de sufrimientos padecida por sus familias. Los nietos señalan que han sido sus padres, tíos $\mathrm{y}$ abuelos quienes vivieron o presenciaron directamente la experiencia de PPT, los principales constructores del relato de la historia de PPT. Fuera del sistema familiar, los nietos acusan la inexistencia de figuras mediatizadoras de dicha historia, hecho que dificulta la posibilidad de integrar su historia personal y familiar en el contexto social.

\section{Conclusiones}

La pregunta central que guió el estudio se orientó a comprender cómo eventos traumáticos provocados por la tortura se transmiten e integran en la trayectoria vital de nietos de ExPP de la dictadura militar chilena. Los relatos de vida construidos por los nietos permiten dar respuesta a esta pregunta, dando cuenta al interior de sus familias de una relación intersubjetiva compleja de transmisión y apropiación de la historia o memoria familiar, donde está presente la experiencia de prisión política y tortura del abuelo, junto con condiciones contextuales y políticas de la historia social. Los nietos o miembros más jóvenes de la familia reciben de los mayores huellas que permiten la reconstrucción y apropiación de la historia familiar de un pasado doloroso que los compromete y que los interpela a posicionarse en el presente y a proyectarse en el futuro como herederos de dicha historia. El relato de vida de los nietos de ExPP permite construir en el presente su historia individual, la cual está conectada con la historia familiar y con la historia social.

Los resultados también permiten señalar que en las familias de ExPP persiste una dinámica de evitación y silencio en torno a la experiencia de tortura, la que determina la relación de los nietos con dicha experiencia traumática. Estos resultados son consistentes con los estudios desarrollados, a nivel nacional, por Becker y Díaz (1998), Díaz (1991, 1995) y Faúndez et al. (1991) con hijos de víctimas de la violencia política. Y a nivel internacional, por Auerhahn y Laub (1998); Bekerman et al. (2009); Bender (2004); Cardoso et al. (2009); Chaitin (2000);Danieli (1998); Edelman et al. (1998); Miñarro y Morandi (2009); Rosenthal (1998); Scapusio et al. (2009).

Así, los nietos de ExPP chilenos, al igual que sus padres, se encuentran enfrentados a una historia o memoria familiar traumática, que constituye en parte su propia identidad. En este sentido, la historia de PPT puede ser definida como una memoria identitariamente relevante (Haye y Carvacho, 2011), que conduce a los jóvenes miembros de la tercera generación a identificarse con la historia familiar traumática y a asumir la posición de nietos de ExPP Ricœur (1985/2009) plantea que la construcción de la propia historia es un criterio de identidad personal. A través de la narración de la historia de vida se constituye el sentido de continuidad que hace que uno sea igual a sí mismo. Así la historia, según este autor, es el presente del pasado, es la continuidad entre pasado y presente que permite remontarnos desde el presente hasta los acontecimientos más lejanos de la infancia. 
La invitación a participar en el estudio actuó como una interpelación para los nietos que los llevó a posicionarse progresivamente, dentro de la trama discursiva, como narradores de la historia de PPT, reproduciendo, modificando y creando significados en torno a esta experiencia. Como ya se señaló, según Jofré (1990) la posición del narrador se refiere a la actitud de mayor o menor cercanía que el hablante tiene para con la historia que narra. Durante la construcción de los relatos de vida, los nietos presentaron diversas posiciones respecto a la historia narrada, por ello se habla de posiciones en plural. Tanto al inicio como a medida que avanzaban en la construcción de sus relatos, los nietos variaron sus posiciones, alcanzando progresivamente una mayor cercanía con la historia contada. Este proceso se dio de manera distinta entre los nietos, quienes asumieron $\mathrm{y}$ variaron sus posiciones frente a la historia narrada en distintos momentos de los encuentros, no existiendo un patrón único ni estable, ni tampoco una relación directa entre la posición del narrador y un único encuentro. Sin embargo, es posible plantear una mayor frecuencia de la posición del narrador testigo en el primer encuentro. Esta posición se caracterizó principalmente por una actitud de distancia emocional con la historia narrada, desde la cual el narrador buscó reconstituir eventos del pasado de otro, entregando un relato basado en hechos y acontecimientos precisos de la historia de PPT del abuelo. Mientras que la posición del narrador protagonista solo se observó en el tercer encuentro, adquiriéndose de forma progresiva, en un proceso de apropiación de la historia de PPT.

El proceso de apropiación de la historia de PPT constó de tres momentos o etapas con características distintas: el inicio del relato, asociado al primer encuentro, en que predominó la posición del narrador testigo; el desarrollo del relato, que se extiende entre el primer y segundo encuentro y en que predominó la posición del narrador involucrado; y el cierre del relato, asociado al último encuentro, en que predominó la posición del narrador protagonista. Cada una de estas etapas, como se señaló anteriormente, posee características propias y distintivas en relación a las posiciones asumidas por los narradores.

Halbwachs (1950/2004) sostiene que existe un vínculo entre las generaciones que asegura que el pasado sea transmitido por los padres y abuelos a las nuevas generaciones, de esta cada persona recibe una herencia de sus predecesores, lo cual asegura la continuidad e identidad social e individual. En esta misma línea, Cornejo, Brackelaire y Mendoza (2009) señalan que la transmisión entre los individuos nunca es de un objeto, sino que siempre es de la alteridad, en el sentido que la transmisión siempre involucra reconstruir la perspectiva del otro para conectarse entre sí en un marco común que permita la comprensión de los diferentes puntos de vista. Es posible, desde los resultados, pensar que los miembros más jóvenes de las familias de ExPP recibieron de los más viejos huellas del pasado traumático que permiten la reconstrucción de la memoria familiar de PPT que los compromete e interpela a posicionarse en el presente, apropiándose de aquellos elementos de la historia familiar que son identitariamente relevantes, y a proyectarse a partir de ellos en el futuro.

Ante el relato familiar fragmentario, y la negativa y falta de reconocimiento social respecto de la historia de PPT, los nietos responden, a través de sus propios relatos, posicionándose como herederos de un legado familiar, de una marca identitaria y asumiéndose como protagonistas de una historia que continúa construyéndose en el presente. De esta manera, en la construcción de sus relatos de vida los nietos se apropian de la historia familiar traumática de $P P T$, integrando la interpretación que ellos hacen de dicho pasado como parte de su propia historia e identidad. En este proceso los nietos funden pasado, presente y futuro, reconstruyendo de otro modo eso que ha sido vivido anteriormente y asumiendo una relación leal de su historia individual con el pasado familiar.

Lo anterior permite afirmar que la construcción de los relatos sin duda contribuyó al proceso de elaboración de la historia familiar traumática. Pero dicha elaboración continúa siendo una tarea inconclusa. Como ya se indicó, los sentidos y significados siempre son construidos en interacción con otros, no solo con los contemporáneos sino también con los predecesores. El sentido construido siempre es sociohistórico y se articula con sentidos previos sedimentados en el tiempo a través de la vida social (Feierstein, 2012). Los nietos de ExPP que participaron en este estudio, en sus relatos acusan el silencio de la sociedad y el Estado chileno frente a la experiencia traumática de sus familias, cuestionan las medidas de reparación y solicitan mayor reconocimiento, justicia y verdad para sus abuelos y familias. Por ello, no es posible plantear la plena elaboración mientras la sociedad y el Estado chileno no asuman este proceso en su conjunto con las víctimas y sus familias.

Los padres y abuelos de los participantes de este estudio sufrieron directamente la violencia política, sistemática, intencional y dirigida por el poder institucionalizado. Lo anterior condujo a estas familias a padecer, en completa indefensión, un trauma psicosocial (Martín-Baró, 1989), caracterizado por la marginalidad, el aislamiento social y la privatización del daño (Lira, Becker y Castillo, 1989). 
En el caso de los nietos, en el transcurso de sus vidas éstos no solo han heredado una historia familiar traumática, sino también han asumido las lealtades familiares (Boszormenyi-Nagy y Spark, 1983/2003) en torno a esta historia que actúan como mandato, moldeando y dirigiendo su comportamiento y la formación de su identidad.

En conclusión, este estudio permite afirmar que tras 41 años del Golpe de Estado en Chile, en el presente existe una generación compuesta por nietos de víctimas de PPT, nacidos en democracia, cuyas vidas se han visto y siguen estando marcadas por la experiencia familiar traumática de PPT. Estos hallazgos dificultan pensar que el fenómeno de la transgeneracionalidad del trauma psicosocial encuentre prontamente su fin, sobre todo si en el país no se generan nuevos espacios de reconocimiento, verdad y justicia para las víctimas que favorezcan los procesos de elaboración del trauma psicosocial.

Se considera que la realización de este tipo de estudios puede aportar conocimiento útil para el desarrollo de políticas de reparación que permitan el reconocimiento social de la historia familiar de las víctimas de la violencia. Del mismo modo, se considera que tanto la propuesta teóricometodológica como los resultados obtenidos en este estudio, aportan pistas para nuevas líneas de investigación, orientadas a la comprensión de la transmisión transgeneracional de diferentes hechos (traumáticos y no traumáticos) del pasado familiar y su impacto en las historias personales. A nivel social, este estudio puede entregar elementos para el análisis y comprensión respecto a la importancia que tienen en las historias personales de los chilenos en la actualidad, acontecimientos del pasado social traumático. De este modo estos resultados son también un aporte histórico a la construcción de la memoria desde parámetros científicos en el mundo académico.

Acerca de las limitaciones del estudio, una se relaciona con el género de las víctimas de PPT y su posible influencia en el proceso de transmisión transgeneracional del trauma psicosocial, pues el género del abuelo ExPP puede ser importante en la comprensión del fenómeno en estudio. Sin embargo, a partir de los resultados de este estudio, no es posible referirse al respecto ya que si bien en dos de los catorce casos estudiados al menos una de las abuelas había sido ExPP, los nietos no integraron en sus relatos elementos que permitieran referirse a diferencias de género entre las víctimas de PPT y su influencia en el proceso de transmisión transgeneracional del trauma psicosocial. Esto ya que en aquel caso en que tanto el abuelo como la abuela fueron detenidos, el nieto habló exclusivamente de la experiencia del abuelo varón lo mismo sucedió en el caso en que la abuela fue la única detenida de la familia. En este último episodio, el narrador se refirió exclusivamente a la participación política del abuelo-varón causante, según el relato del nieto, de la detención de su abuela. Una segunda limitación se relaciona con que la totalidad de los nietos que participaron en este estudio pertenecen a familias cuyos padres y/o abuelos forman parte de agrupaciones de ExPP o de DD.HH., y con que al momento de la realización del estudio, solo uno de los abuelos ExPP no se encontraba calificado por la CNPPT (2004), debido a que después de su muerte su familia no quiso entregar su testimonio a la comisión. Se trata de dos antecedentes relevantes que, sin duda, caracterizan a un amplio sector de las víctimas de PPT, pero que abren la interrogante acerca de los factores singulares y posibles diferencias que podrían presentarse en aquellas familias que han seguido trayectorias distintas. Por ello, se considera como proyección de este estudio la realización de nuevas investigaciones que permitan profundizar en las experiencias de familias cuyos padres y abuelos no mantengan participación social ni política y optado por no entregar sus testimonios a las comisiones calificadoras.

\section{Referencias}

Abraham, N., y Torok, M. (1978/2005). Corteza y Núcleo. Buenos Aires: Amorrortu.

Albeck, H. J. (1993). Intergenerational consequences of trauma: Reframing traps in treatment theory: A second generation perspective. En M. O. Williams y J. F. Sommer (Eds.), Handbook of Post-Traumatic Therapy. Westport, CT: Greenwood Press, 106-125. Extraído desde http://www. questia.com/.PM.qst?a=oydocId=28018149

Altounian, J. (2008). De l'élaboration d'un héritage traumatique. Cliniques méditerranéennes, 78, 7-22.

Améry, J. (1966/2010). Par-delà le crime et le châtiment. Essai pour surmonter l'insurmontable. París, Francia: Babel.

Auerhahn, N., y Laub, D. (1998). Intergenerational memory of the Holocaust. En Y., Danieli (Ed.), International Handbook of Multigenerational Legacies of Trauma (pp. 21-41). New York: Plenum Press.

Barocas, H., y Barocas, C. (1973). Manifestations of concentration camp effects on the second generation. American Journal of Psychiatry, 103, 810-821.

Becker, D., y Díaz, M. (1998).The social process and the transgenerational transmission of trauma in Chile. En Y. Danieli (Ed.), International Handbook of Multigenerational Legacies of Trauma (pp. 435-445). New York: Plenum Press.

Bekerman, S., Soutric, L., Pezet, Y., Mazur, V., Oberti, C., y Lagos, M. (2009). Terrorismo de Estado: segunda generación. En M., Lagos, V., Vital, B., Brinkmann y M., Scapucio (Eds.), Daño transgeneracional: consecuencias de la represión politica en el cono sur (pp. 147-146). Santiago: LOM Ediciones.

Bender, S. (2004). Transgenerational effects of the holocaust: Past, present and future. Journal of Loss and Trauma 9, 205-215.

Biederman, N. (1991). Detenidos desaparecidos: consecuencias para la segunda generación. En CINTRAS (Ed.), II seminario de la región del Maule: Derechos humanos, salud mental, atención primaria: desafío regional (pp. 170-176). Santiago: CINTRAS. 
Boszormenyi-Nagy, I., y Spark, G. M. (1983/2003). Lealtades invisibles: Reciprocidad en terapia familiar intergeneracional. Buenos Aires: Amorrortu.

Breuer, J., y Freud, S. (1893/1976). Los estudios sobre la histeria. En J. Strachey y A. Freud (Eds.), Obras completas de Sigmund Freud, Vol. II. Buenos Aires: Amorrortu.

Brinkmann, B., Guzmán, J. M., Madariaga, C., y Sandoval, M. (2009). Daño transgeneracional en descendientes de sobrevivientes de tortura. En M. Lagos, V. Vital, B. Brinkmann y M. Scapucio (Eds.), Daño transgeneracional: consecuencias de la represión política en el cono sur (pp. 15-146). Santiago: LOM Ediciones.

Cardoso, C., Calhau, J., Knijnik, L., Kolker, T. y Vital, V. (2009). Efectos transgeneracionales de la violencia de Estado. En M. Lagos, V. Vital, B. Brinkmann y M. Scapucio (Eds.), Daño transgeneracional: consecuencias de la represión política en el cono sur (pp. 249-325). Santiago: LOM Ediciones.

Castillo, M. I. (2009). Transmisión de la Violencia y Memoria Social. Revista Praxis, 15, 99-114

Chaitin, J. (2000). Facing the Holocaust in generations of families of survivors: The case of partial relevance and interpersonal values. Contemporary Family Therapy, 22, 289-313.

Comisión Nacional sobre Prisión Política y Tortura (2004). Informe de la Comisión Nacional sobre Prisión Política y Tortura. Santiago, Chile: Autor. Extraído desde http://www.ben.cl/bibliodigital/dhisto/ lfs/Informe.pdf

Comisión Presidencial Asesora para la Calificación de Detenidos Desaparecidos, Ejecutados Políticos y Víctimas de Prisión Política y Tortura (2011). Informe de la Comisión Presidencial Asesora para la Calificación de Detenidos Desaparecidos, Ejecutados Políticos y Victimas de Prisión Politica y Tortura. Santiago, Chile: Autor. Extraído desde http:// www.indh.cl/wp-content/uploads/2011/10/Informe2011.pdf

Cornejo, M. (2006). El enfoque biográfico: trayectorias, desarrollos teóricos y perspectivas. Psykhe, 15, 95-106.

Cornejo, M. (2008). Political exile and the construction of identity: A life stories approach. Journal of Community and Applied Social Psychology, $18,333-348$

Cornejo, M. y Salas, N. (2011). Rigor y Calidad Metodológicos: Un Reto a la Investigación Social Cualitativa. Psicoperspectivas, 10, 12-34.

Cornejo, M., Besoaín, C. y Mendoza, F. (2011). Desafíos en la generación de conocimiento en la investigación social cualitativa contemporánea [94 párrafos]. Forum: Qualitative Social Research, 12.

Cornejo, M., Brackelaire, J. L. y Mendoza, F. (2009). Des chaînes du silence à la chaîne de l'écoute. Cahiers de Psychologie Clinique, 32, 205-231.

Cornejo, M., Mendoza, F. y Rojas, R. (2008). La investigación con relatos de vida: Pistas y opciones de diseño metodológico. Psykhe, 17, 29-39.

Cornejo, M., Morales, G., Kovalskys, J. y Sharim, D. (2013). La escucha de la tortura desde el Estado: la experiencia de los profesionales de la Comisión Nacional sobre Prisión Política y Tortura en Chile. Universitas Psychologica, 12, 271-284.

Cornejo, M., Rojas, R., Buzonni, M. E., Mendoza, F., Concha, M. y Cabach, C. (2007). Prisión Política y Tortura: Desde las Intervenciones Psicosociales a las Políticas de Reparación. Persona y Sociedad, 1, 59-81.

Danieli, Y. (1998). Conclusions and future directions.En Y. Danieli (Ed.), International Handbook of Multigenerational Legacies of Trauma (pp. 669-690). New York: Plenum Press.

De Gaulejac, V. (1987). La névrose de classe. Paris: Hommes y Groupes.

De Villers, G. (1996). L'approche biographique au carrefour de la formation des adultes, de la recherche et de l'intervention. Le récit de vie comme approche de recherche-formation. En D. Desmarais y J.-M. Pilon (Eds.), Pratique des histoires de vie (pp. 107-134). Paris: L'Harmattan.

Deutsch, A. (2007). Secuelas de la tortura en el individuo, la familia y la sociedad. En L. Berrón y G. Espinosa (Eds.), Atención integral a víctimas de tortura en procesos de litigio. Aportes Psicosociales (pp. 247-274). San José: Instituto Interamericano de Derechos Humanos.

Díaz, M. (1995). Familia y represión política: trauma y contexto social: consecuencias transgeneracionales. Proposiciones, 26, 208-219.
Edelman, L., Kordon, D. y Lagos, D. (1998). Transmission of Trauma. The Argentine Case. En Y. Danieli (Ed.), International Handbook of Multigenerational Legacies of Trauma (pp. 447-463). New York: Plenum Press.

Faúndez, H., Estrada, A., Balogi, S., y Hering, M. (1991). Cuando el fantasma es un tótem: perturbaciones en las interacciones afectivas de adultos jóvenes, hijos de detenidos desaparecidos. En P. Rojas (Ed.), Persona, Estado, Poder. Estudios sobre salud mental (pp. 223-241). Santiago: LOM

Faúndez, X. (2013). Transgeneracionalidad del trauma psicosocial en nietos de ex presos politicos de la dictadura militar chilena 19731990: Transmisión y apropiación de la historia de prisión politica $y$ tortura (Tesis de Doctorado no publicada), Pontificia Universidad Católica de Chile.

Faúndez, X., Brackelaire, J. L. y Cornejo, M. (2013).Transgeneracionalidad del Trauma Psicosocial: Imágenes de la Detención de Presos Políticos de la Dictadura Militar Chilena, Reconstruidas por los Nietos. Psykhe, 22, 83-95.

Faúndez, X. y Cornejo, M. (2010). Aproximaciones al estudio de la transmisión transgeneracional del trauma psicosocial. Revista de Psicología, 19, 31-54.

Feierstein, D. (2012). Memorias y representaciones: Sobre la elaboración del genocidio. Buenos Aires: Fondo de Cultura Económica.

Freud, S. (1914/1976). Recordar, repetir y reelaborar. En J. Strachey y A. Freud (Eds.), Obras completas de Sigmund Freud, Vol. XII. Buenos Aires: Amorrortu.

Gergen, K. (1996). Realidades y relaciones. Aproximaciones a la construcción social. Barcelona: Paidós.

Glaser, B. y Strauss, A. (1967). El desarrollo de la teoría fundada. Chicago, Illinois: Aldine.

Haye, A. y Carvacho, H. (2011). Memoria a través de las generaciones: persistencia ideológica y recuerdos negadores. En C. Aguilera y R. Milán (Eds.), Ciudadanía y Memoria: Desarrollo de sitios de conciencia para el aprendizaje en Derechos Humanos (pp. 134-150). Santiago: Corporación Parque por la Paz Villa Grimaldi.

Halbwachs, M. (1950/2004). La memoria colectiva. Zaragoza: Prensas Universitarias de Zaragoza.

Jofré, M. (1990). Teoría literaria y semiótica. Santiago, Chile: Editorial Universitaria.

Kaës, R. (2006). Rupturas catastróficas y trabajo de la memoria. Notas para una investigación. En J. Puget y R. Kaës (Eds.), Violencia de Estado y psicoanálisis (pp. 159-187). Buenos Aires: Lumen.

Ricœur, P. (1985/2009). Tiempo y narración, tomo III. El tiempo narrado. Madrid: Siglo XXI.

Ricœur, P. (1995). Teoría de la interpretación: discurso y excedente de sentido. México: Siglo Veintiuno Editores.

Kupelian, D., Kalayjian, A. S. y Kassabian, A. (1998). The Turkish genocide of the Armenians. Continuing effects on survivors and their families eight decades after massive trauma. En Danieli, Y. (Ed.), International Handbook of Multigenerational Legacies of Trauma (pp. 191-210). New York: Plenum Press.

Kinzie, D., Boehnlein, J. y Sack, W. (1998). The effects of massive trauma on Cambodian parents and chlidren. En Y. Danieli (Ed.), International Handbook of Multigenerational Legacies of Trauma (pp. 211-221). New York: Plenum Press.

Lee, R. (1993). Doing research on sensitive topics. Newbury Park, CA: Sage.

Legrand, M. (1993). L'approche biographique. Théorie, clinique. Paris: Hommes et Perspectives.

Legrand, M. (1999). La contra-transferencia del investigador en los relatos de vida. Proposiciones, 29, 115-121.

Lejeune, P. (1991). El pacto autobiográfico. Anthropos 29, 47-62.

Lev-Wiesel, R. (2007). Intergenerational transmission of trauma across three generations: A preliminary study. Qualitative Social Work, 6, 75-94.

Lira, E. y Castillo, M. I. (1991). Psicología de la amenaza política y del miedo. Santiago, Chile: Instituto Latinoamericano de Salud Mental y Derechos Humanos. 
Lira, E. (1990). Psicología del miedo y conducta colectiva en Chile. En I. Martín-Baró (Ed.), Psicología social de la guerra: trauma y terapia (pp. 22-25). San Salvador: UCA Editores.

Lira, E. (2011). Verdad, reparación y justicia: el pasado que sigue vivo en el presente. En Instituto Interamericano de Derechos Humanos (Ed.), Contribución a las políticas de verdad, justicia y reparación a las democracias en América Latina (pp. 85-127). San José, Costa-Rica: Publicaciones del Instituto Interamericano de Derechos Humanos.

Lira, E., Becker, D. y Castillo, M. I. (1989). Derechos humanos: todo es según el dolor con que se mira. Santiago, Chile: Instituto Latinoamericano de Salud Mental y Derechos Humanos.

Lyotard, J. F. (1984). La condición postmoderna. Informe sobre el saber. Madrid: Cátedra.

Martín-Baró, I. (1989). La violencia política y la guerra como causas en el país del trauma psicosocial. Revista de Psicología de El Salvador, 28, 123-141.

Martín-Baró, I. (1990). Psicología Social de la Guerra: Trauma y Terapia. San Salvador: UCA Editores.

Minoletti, A. (2002). Norma técnica para la atención de personas afectadas por la represión política ejercida por el Estado en el periodo 1973-1990. Ministerio de Salud. Gobierno de Chile.

Miñarro, A. y Morandi, T. (2009). Trauma psíquic i transmissió intergeneracional. Barcelona: Fundació Congrés Catalá de Salut Mental.

Morales, G. y Cornejo, M. (2013). Ambivalencias en la Escucha de la Tortura en Chile: Implicancias Clínica y Sociales. Terapia Psicológica, 2, 197-208.

Morales, L. (2001). La escritura de al lado. Géneros referenciales. Santiago: Editorial Cuarto Propio.

Puget, J. (2006). Violencia social y psicoanálisis. De lo ajeno-estructurante a lo ajeno-ajenizante. En J. Puget y R. Kaës (Eds.), Violencia de Estado y psicoanálisis (pp. 57-75). Buenos Aires: Lumen.

Ricœur, P. (1995). Teoría de la interpretación: discurso y excedente de sentido. México: Siglo Veintiuno Editores.

Rosenthal, G. (1998). The Holocaust in three generations: Families of victims and perpetrators of the Nazi regime. London: Kassel.
Roulston, K., De Marrais, K. y Lewis, J. (2003). Learning to interview in the social sciences. Qualitative Inquiry, 9, 643-668.

Rowland-Klein, D. (2004). The transmission of trauma across generations: Identification with parental trauma in children of Holocaust survivors. En Cayherall, D.R. (Ed.), Handbook the stress, trauma and family (pp. 117-138). New York: Brunner-Routledge.

Sandoval, J. (2013). Una Perspectiva Situada de la Investigación Cualitativa en Ciencias Sociales. Cinta de Moebio, 46, 37-46.

Scapusio, M., Pache, S., Ortiz, C. y Ruiz, M. (2009). Efectos transgeneracionales del daño psicosocial ocasionado por el terrorismo de Estado. En M. Lagos, V. Vital, B. Brinkmann y M. Scapucio (Eds.), Daño transgeneracional: consecuencias de la represión política en el cono sur (pp. 329-440). Santiago: LOM.

Storolow, R. D. y Atwood, G. E. (2004). Los contextos del ser: las bases intersubjetivas de la vida psíquica. Barcelona: Herder.

Strauss, A. y Corbin, J. (2002). Bases de la investigación cualitativa. Técnicas y procedimientos para desarrollar la teoría fundamentada. Medellín, Colombia: Editorial Universidad de Antioquia.

Tatara, M. (1998). The second generation of hibakusha atomic bomb survivors. A psychologist view. En Y. Danieli (Ed.), International Handbook of Multigenerational Legacies of Trauma (pp. 141-146). New York: Plenum Press.

Tisseron, S. (1995/2001). Le psychisme á l'épreuve des générations. Clinique du fantôme. París: Dunod.

Van Dijk, T. (1978). La ciencia del texto. Barcelona: Paidós.

Vasilachis de Gialdino, I. (2009). Los fundamentos ontológicos y epistemológicos de la investigación cualitativa [92 párrafos]. Forum: Qualitative Social Research, 10.

Viñar, M. (2006). Violencia social y realidad en psicoanálisis. En J. Puget y R. Kaës (Eds.), Violencia de Estado y psicoanálisis (pp. 57-75). Buenos Aires: Lumen.

Volkan, V. (1996). Bosnia-Herzegovina: Ancient fuel for a modern inferno. Mind and Human Interaction, 7, 110-127. 